\title{
Restyling para una nueva etapa
}

\author{
Restyling to face a new era
}

\section{Carlos Aguilera-Serrano, Rocío Juliá-Sanchis, Vanessa Sánchez Martínez}

Consejo de redacción: Revista Española de Enfermería de Salud Mental.

Contacto: Vanessa Sánchez Martínez, reesme@reesme.com

Se publica el número 13 de la Revista Española de Enfermería de Salud Mental (REESME), y alcanza esta cifra emblemática como una publicación científica consolidada e influyente de los cuidados enfermeros de salud mental en español. Editada por la Asociación Española de Enfermería de Salud Mental (AEESME), es una publicación cuatrimestral, con procedimientos de arbitraje rigurosos y accesible en abierto. Se distribuye a su lista de suscriptores y suscriptoras, a los principales centros asistenciales y de investigación, escuelas o facultades de Enfermería y sociedades científicas, favoreciendo su difusión entre los y las profesionales de la salud que puedan beneficiarse de sus contenidos.

La REESME es una herramienta para la divulgación científica sin ánimo de lucro, gratuita tanto para quienes producen artículos como para quienes los consumen. Además, la REESME está indexada en diferentes bases de datos o repositorios: Biblioteca digital CECOVA, Dialnet, Dulcinea, LatIndex, Road y Trobes, dando visibilidad a los cuidados enfermeros de salud mental en español.

Desde el consejo de redacción, apreciamos la valía de los cimientos sobre los que se sustenta el desarrollo de esta revista, que se fraguaron gracias a la encomiable dedicación y labor de las distintas personas que han dirigido la REESME desde su antecedente PRESENCIA (Revista de Enfermería de Salud Mental, fruto de un acuerdo mantenido entre la AEESME con la Fundación INDEX entre los años 2005 y 2015), como el ilustre Dr. Pacheco-Borrella, el estimado Dr. Castro-Molina, o el más reciente, el apreciado Sr. Sánchez-Alfonso. Deseamos seguir la estela de su implicación para ofrecer a los y las enfermeras producción científica en salud mental actualizada, de calidad y legitimada por sus procesos de revisión por pares.

La REESME pretende ser el reflejo de la evolución de la disciplina científica a través de contenidos que sirvan de base para la mejora de la docencia, investigación, gestión y práctica asistencial. Nuestro objetivo es dinamizar temas de interés, teóricos o prácticos, en forma de publicaciones relevantes, que ofrezcan el enriquecimiento a sus lectores y lectoras, que promuevan la discusión y mejoren la erudición y la práctica de la enfermería de salud mental. Como evolución de la línea editorial, se han creado nuevas secciones, como los cuidados, los protocolos de investigación o las experiencias vividas en primera persona. Para alcanzar nuestro objetivo y dotar de contenidos a esta estructura, son imprescindibles sus contribuciones, que les invitamos a presentar. Serán bienvenidos trabajos que, dentro del marco general de las ciencias de la salud, contribuyan al desarrollo y a la formación continuada de los y las enfermeras de salud mental.

Para terminar, como consejo de redacción deseamos dar las gracias: a la AEESME por confiar en nuestra labor, a los autores y autoras por hacernos llegar sus investigaciones y experiencias, al comité editorial y al conjunto de revisores y revisoras por asegurar la aptitud y el rigor de las publicaciones, y también a todas las personas que las leen. Por nuestra parte, les transmitimos el compromiso de esforzarnos para seguir viendo crecer esta revista. 